\title{
ABRAHAM PALATNIK: A LUZ COMO EXPRESSÃO PLÁSTICA
}

Abraham Palatnik: light as plastic expression

Abraham Palatnik: la luz como expresión plástica

> Almerinda da Silva Lopes (Universidade Federal do Espírito Santo, Brasil)*

LOPES, Almerinda da Silva. Abraham Palatnik: a luz como expressão plástica. Revista Poiésis, Niterói, v. 23, n. 39, p. 170-186, jan./jun. 2022. [DOI: https:// doi.org/10.22409/ poiesis.v23i39.50822]

Este documento é distribuído nos termos da licença Creative Commons Atribuição Não Comercial 4.0 Internacional (CC-BYNC) (C) 2022 Almerinda da Silva Lopes.

Submetido:

13/7/2020; Aceito:

$31 / 8 / 2021$
RESUMO $O$ texto reflete sobre a criação do Aparelho Cinecromático de autoria do brasileiro Abraham Palatnik (1925-2019) e sua participação na I Bienal Internacional de São Paulo (1951), bem como a dificuldade da crítica brasileira em dialogar com o inusitado objeto dotado de luz em movimento, por se distanciar do tradicional duopólio artístico, embora o mesmo não deixasse de se insinuar simultaneamente como objeto escultórico e pictórico. Embora esse pioneiro objeto cinético não deixasse de se mostrar tributário do Modulador de Espaço-Luz (1930), de autoria do artista húngaro Moholy-Nagy, o brasileiro Abraham Palatnik revelou ousadia e perseverança ao criar sua primeira obra luminocromática em um país que, na época, era muito defasado tecnologicamente.

PALAVRAS-CHAVE arte cinética; Abraham Palatnik; aparelho cinecromático; arte e tecnologia; relação espaço/luz/tempo

*Almerinda da Silva Lopes é Professora e Pesquisadora dos Programas de Pós-Graduação em Artes (PPGA) e em História (PPGHIS) da Universidade Federal do Espírito Santo (UFES). E-mail: almerindalopes579@gmail.com. Orcid: https://orcid.org/0000-0001-50757843 0000-0001-5075-7843 
ABSTRACT The text reflects on the creation of the Cinechromatic Apparatus authored by the Brazilian Abraham Palatnik (1925-2020) and his participation in the 1st São Paulo International Biennial (1951), as well as the difficulty of Brazilian critics to dialogue with the unusual object endowed with light in movement, for distancing itself from the traditional artistic duopoly, although it did not fail to insinuate itself simultaneously as a sculptural and pictorial object. Although this pioneering kinetic object was still a tributary of the Space-Light Modulator (1930), by the Hungarian artist Moholy-Nagy, the Brazilian Abraham Palatnik showed boldness and perseverance when creating his first lumino-chromatic work in a country which, at the time, was very technologically outdated.

KEYWORDS Kinetic Art; Abraham Palatnik; kinechromatic apparatus; art and technology; space/light/ time relation

RESUMEN El texto reflexiona sobre la creación del Aparato Cinecromático, del brasileño Abraham Palatnik (1925-2019) y su participación en la I Bienal Internacional de São Paulo (1951), así como la dificultad de la crítica brasileña para dialogar con el objeto insólito dotado de luz en movimiento, por alejarse del tradicional duopolio artístico, aunque no deja de insinuarse a la vez como objeto escultórico y pictórico. Aunque este objeto cinético pionero era todavía afluente del Space-Light Modulator (1930), del artista húngaro Moholy-Nagy, el brasileño Abraham Palatnik mostró audacia y perseverancia al crear su primera obra lumino-cromática en un país que, en ese momento, estaba muy desactualizado tecnológicamente. PALABRAS CLAVE arte cinético; Abraham Palatnik; aparato cinecromático; arte y tecnología; relación espacio/ luz/tiempo 


\section{INTRODUÇÃO}

A Revolução Industrial instaurou um processo de crise e de ruptura com os valores espirituais e os paradigmas estéticos do passado. Gerou, ainda, um clima propício ao capitalismo, ao racionalismo e à difusão da ideia de progresso, associados a uma nova ordem social e econômica pautada no funcionalismo da máquina, que assumia o papel de libertadora do trabalhador moderno. A eficiência da máquina possibilitaria o aumento da produção e estimularia o consumo, que trariam mudanças na estrutura urbana, no pensamento e nos modos de vida.

A esse "espírito positivo", de base instrumental e pragmática, vinculava-se, ainda, a ideia de autonomia do fenômeno criativo e de um novo estatuto da arte. Os artistas passariam, então, a dialogar mais efetivamente com a ciência e a recorrer às novas tecnologias disponíveis. Buscariam, ainda, angariar melhor posição social competindo livremente no mercado e comercializando os objetos artísticos com quem tivesse interesse e recursos para adquiri-los.

O desenvolvimento das tecnologias e de materiais industriais possibilitou a descoberta da fotografia, da luz elétrica e do cinematógrafo, fenômenos que fascinaram os artistas e lhes impuseram novos desafios, entre eles a possibilidade de solucionar duas antigas aspirações: pintar com a luz e demover a arte de sua característica imobilidade. Com base na tecnologia e nos conhecimentos científicos, as vanguardas mais radicais formularam novos paradigmas para a arte, subvertendo o antigo sistema de representação e os valores estéticos passadistas.

A arte deixava de pautar-se numa ordem espiritual, para inserir-se como meio de expressão, conhecimento específico e bem de mercado. Com os avanços tecnológico e industrial, a arte deixava de ser produto executado exclusivamente de maneira manual e até individual. Os artistas passam a legar a execução de determinadas obras a terceiros ou aos operários das fábricas, prática essa adotada pela Bauhaus, no início do século passado, instituição que propugnou abolir a fronteira entre o artista e o artesão, criador e executor, e que também contribuiu para os primórdios da arte cinética na Europa, como veremos.

Ao vincularem a praxe artística ao espírito funcionalista da vida moderna, os artistas passam a investir em dispositivos tecnológicos, objetivando imprimir dinamismo às formas, linhas e cores. Os antigos efeitos gráficos obtidos com hachuras e sombreados, para simular o movimento de cabelos, roupas, volume do corpo humano e outros entes da natureza, passam a ser questionados e rejeitados por 
seu caráter ilusório, sendo substituídos por artifícios eletromecânicos e materiais industriais.

Se a invenção da fotografia não solucionara essa aspiração, logo surgiriam outras experiências articuladas na simbiose arte/ciência, visando demover os objetos artísticos da imobilidade. Essas pesquisas implicaram o surgimento de novos dispositivos tecnológicos e o aperfeiçoamento dos processos fotográficos, possibilitando gerar imagens dotadas de luz e movimento, pôr em xeque o espaço euclidiano, a perspectiva linear e desmontar algumas concepções da pintura retiniana. O processo mimético ou representativo do mundo objetivo ou analógico seria ironizado e confrontado, abrindo espaço à experiência criativa e ao pensamento científico.

\section{OS NOVOS MECANISMOS PARA IMPRIMIR MOVIMENTO ÀS FORMAS}

Alguns investimentos científicos e a fotografia mostraram que o mundo é dinâmico, modificando-se constantemente, o que contribuiu para repensar os processos de criação em vigor. A fotografia, além de modificar a geração de imagens e instigar o estatuto de arte, imporia mudanças na maneira de compreender e representar o mundo, especialmente a partir do impressionismo, quando a "representação imutável das coisas era abalada e relativizada" e sua "aparência passava a ser determinada pelo Tempo, pela Luz e pelo Movimento" [BIHALJI-MERIN, 1970, p. 60-61].

O advento da luz elétrica, na segunda metade do século XIX, possibilitou a criação do cinema, solucionando, finalmente, a dificuldade de imprimir movimento às imagens. Embora esse movimento fosse apenas ficcional, o cinema iludiria o olho, fazendo-o acreditar que tudo é instável ou se movimenta. Na verdade, é a projeção sequencial e simultânea de uma mesma imagem que gera essa percepção postiça de mundo dinâmico, levando o olho a visualizar as imagens como se dotadas de movimento real. O cinema criava, assim, uma nova "subjetividade e um novo conceito de verdade, que emerge da imaginação e impede distinguir o falso do verdadeiro, a cópia do original, a realidade da ilusão". Além disso, o tempo no movimento do cinema transcorre de maneira "muito mais rápida ou mais lenta do que aquele que vivemos" [PARENTE, 1993, p. 16-20].

O caráter enunciativo do cinema e seu princípio de homogeneização fascinaram os artistas vanguardistas, em especial cubistas, futuristas e construtivistas. Esses exaltaram, em seus respectivos programas teóricos e estéticos, a velocidade da máquina, o cinema, a indústria e as massas urbanas em movimento, em ambientes de diversão ou 
rumando para o trabalho nas efervescentes metrópoles modernas. O cinema transforma-se, assim, na expressão do futuro, desbancando a pintura e a escultura, que deixariam de ser meios privilegiados de informação e de representação visual. Tornou, ainda, os artistas conscientes da impossibilidade de criar obras em movimento se não recorressem a artifícios eletromecânicos, o que Ihes impôs inevitáveis desafios técnicos para desenvolverem experiências nesse âmbito. Isso não impediria, porém, que um número significativo de signatários desenvolvesse, individualmente ou em parceria com técnicos e engenheiros, ainda no início do século XX, experiências no campo artístico e cinematográfico, recorrendo a inusitadas engenhocas mecânicas com tal finalidade, que levariam à criação dos primeiros objetos cinéticos, palavra derivada do inglês Kinetic [ou do grego Kinetiké=cinemático]. vale citar, entre outras, as pesquisas experimentais realizadas por Léger, Picabia e Duchamp, respectivamente em Ballet Mécanique, Entr'acte e Anémic Cinéma, entre 1924 e 1926. Léger já havia realizado, em conjunto com Abel Gance, o filme La Roue[A Roda, 1922] e publicado textos reveladores de seu fascínio pela máquina e pela vida moderna.

O aumento da produção de materiais industriais e de novas tecnologias, a partir dessa mesma década, possibilitou o desenvolvimento de engenhocas artísticas pioneiras, dotadas de luz e movimento. Consistiam em objetos movidos por pequenos motores, como os de autoria de Naum Gabo, Marcel Duchamp e Moholy-Nagy. Quando acionados, alguns componentes desses objetos esculturais se movimentavam, produzindo algum tipo de ação, efeito visual, luminoso ou sonoro.

Em colaboração com um engenheiro, Marcel Duchamp construiu seu primeiro mecanismo ótico, as Placas de vidro rotativas [1923], seguido de outra proposta mais sofisticada, a Semi-esfera Rotativa [Ótica de Precisão, 1925]. Trata-se de objeto-máquina de pequenas dimensões, dotado de uma forma circular de madeira, pintada de branco, contendo uma incisão no centro, sobre a qual o artista desenhou círculos concêntricos pretos. Essa peça foi montada "sobre um disco de cobre, e escondida em uma redoma de vidro coberta de veludo preto". Impulsionado por pequeno motor, o disco girava, fazendo com que as linhas das circunferências concêntricas pintadas em sua superfície "parecessem mover-se para frente e para trás no espaço" [TOMKINS, 2004, p. 284].

O húngaro Lászlo Moholy-Nagy [1895-1946] desenvolveu, nessa época, pesquisas em diferentes linhas de investigação: pintura, escultura, fotografia, cinema, design. Os conhecidos fotogramas criados pelo artista, resultantes do posicionamento de objetos so- 
bre superfícies de papel fotossensível, concretizaram sua vontade de desenhar com a luz. Esses desenhos fotográficos redimensionaram seu interesse por materiais industriais e processos artísticos inusitados, e desencadearam o desenvolvimento de novas experiências artísticas, quando se declarou também instigado pela pintura Quadrado branco sobre fundo branco [1918], de Malevich, e pela atmosfera criada pela luz elétrica sobre a paisagem urbana. As experimentações com luz, cor, forma e movimento levaram Moholy-Nagy a profetizar, ainda, sobre a mudança de postura do espectador, mencionando em manifesto lançado em parceria com Alfred Kemeny, em 1922, que o público passaria de contemplador passivo à posição de participante ativo da obra de arte [BARRET, 1991, p. 153].

As experiências artísticas e concepções teóricas de Moholy-Nagy foram explicitadas no livro The New Vision [1928], desenvolvidas enquanto era professor da Bauhaus [1923-1928], em que refletiu sobre espacialidade, luminosidade e desmaterialização, sobre os efeitos do movimento e da luz sobre a percepção e a recepção dos novos objetos artísticos, que o levaram à criação da primeira escultura cinética: Modulador de Espaço-Luz [Light-Space Modulator, 1922-1930].

Essa complexa estrutura rotativa reuniu variados objetos e materiais: prismas, espelhos, cerca de 70 lâmpadas elétricas, brancas e coloridas, refletores, discos perfurados de metal polido, grades aramadas, esfera de madeira, motor elétrico escondido na base circular da escultura, correntes e rolamentos. O motor fazia a peça girar e as lâmpadas acenderem, emitindo luz que reverberava sobre as superfícies metálicas, criando sombras misteriosas e curiosos efeitos luminoespaciais.

O Modulador foi exibido pela primeira vez na exposição da Federação Alemã de Trabalho, em Paris [1930]. Os efeitos luminosos produzidos pelo objeto-máquina foram registrados, no mesmo ano, no filme dirigido pelo artista, Light Display Black-White-Grey [16 mm]. O aparelho foi utilizado, depois, para produzir efeitos luminosos e ritmos dinâmicos e esfuziantes em fachadas de edifícios, salas de teatro, ópera e balé, obtendo maior impacto com a sala inteiramente escura, pois as sombras assumiam configurações espetaculares, resultantes da combinação de luz branca e colorida provenientes das lâmpadas elétricas. Moholy-Nagy teria se inspirado no romantismo alemão para propugnar o conceito de arte total, com a integração de todas as artes, no que chamou de Teatro da Totalidade, em que os efeitos de luz tomariam todo o espaço, projetando-se sobre os atores e o público. Nesse processo, todos os elementos teriam a mesma importância, eliminando as hierarquias e outorgando a substituição dos atores pelo 
movimento dinâmico da projeção, reflexões essas explicitadas no livro Vision in Motion [1947], publicado logo após a morte do artista.

O Modulador tornou a luz matéria escultural e princípio de dissolução da forma, pondo em crise a resistência e a perenidade dos materiais. A luz que emanava do objeto dissolvia a rigidez de suas estruturas metálicas, tornando a matéria translúcida e reverberante, gerando efeitos simultâneos no espaço. O funcionamento do objeto com a utilização de pequeno motor, o aprisionamento de lâmpadas elétricas num compartimento/caixa e a ideia de luz como moduladora do tempo e do espaço pautaram as experiências desenvolvidas cerca de vinte anos depois pelo brasileiro Abraham Palatnik, que certamente conhecia o Modulador, como veremos.

\section{MOLDAR O TEMPO, ORGANIZAR O CAOS, PINTAR COM A LUZ}

Abraham Palatnik [1928-2020], ao retornar de Telaviv [Israel] e se fixar no Rio de Janeiro [1947], era um jovem de dezenove anos, pintor de retratos, naturezas mortas e paisagens de tendência expressionista, como atestam as telas que enviou à Divisão Moderna do Salão Nacional de Belas Artes [1948]. Rapidamente se integrou ao ambiente artístico carioca, aproximando-se de artistas da nova geração, como Almir Mavignier, que o apresentou a Mário Pedrosa. Convidado pelo amigo para conhecer o ateliê de arte do Centro Psiquiátrico D. Pedro II, em Engenho de Dentro [RJ] - atual Instituto Municipal Nise da Silveira -, Palatnik se revelou impactado pelos trabalhos dos alienados, passando a questionar seu próprio processo expressivo. Numa das reuniões na casa de Mario Pedrosa, em que se refletia sobre arte, o crítico sugeriu-Ihe a leitura de livros sobre a Teoria da Gestalt e a realização de pesquisas aplicando os conhecimentos de matemática, física e tecnologia adquiridos em Telaviv. Sem abandonar definitivamente a pintura, o jovem realiza experimentações, visando encontrar novos meios de expressão sem recorrer "à instrumentária clássica, isto é, pincel, tinta, cavalete", como declarou ao jornal Tribuna da Imprensa [1951]. Depois de quase dois anos de tentativas insatisfatórias, Palatnik concluiu um inusitado objeto construído com materiais industriais, que pintava com a luz, concretizando assim um antigo sonho. Tratava-se de uma caixa de madeira, com uma das faces revestida por tecido de nylon, no interior da qual inseriu lentes, cilindros de madeira, com faixas de várias cores, inúmeras lâmpadas elétricas, de diferentes voltagens, conectadas a 600 metros de fio e pequeno motor extraído de um ventilador doméstico, que ligava as lâmpadas e fazia girar os cilindros. A luz que emana 
das lâmpadas incide sobre os carretéis e sobre a superfície refratária das lentes, mudando de direção, o que provoca uma mistura ótica de cores-luz no interior da caixa, que projetada na tela ou écran de nylon sugere uma pintura abstrata mutante, cujo movimento e duração temporal são controlados por contatos elétricos.

O objeto, concluído no início de 1950, é apresentado pelo artista a Mário Pedrosa, que o batizou de Aparelho Cinecromático [PALATNIK, 1951, p. 5]. Fascinado com a invenção, o artista teria declarado ao crítico: "O que o pintor faz com a tinta eu faço com a luz", além de preconizar também a participação público/obra, ideia que, no entanto, parece ter sido também apropriada de Moholy-Nagy. A duração da projeção desse primeiro aparelho foi programada para durar quinze minutos, desligando-se automaticamente ao final do ciclo, cabendo aos espectadores decidirem ligá-lo novamente ou não, para reverem a repetição do evento performático da máquina. Como ocorre no cinema, ao toque do interruptor instalado na lateral externa da caixa, tornava-se possível ligar o Cinecromático e rever a repetição do espetáculo pictórico de formas e cores/luz em movimento, durante o tempo programado pelo artista por meio do pequeno timer, numa alusão ao "eterno retorno". O processo interativo, embora exija algum tipo de ação e reação do interlocutor, não interfere no desempenho da máquina, pois tudo está previamente programado pelo artista. Embora a ideia de participação ou de interação público/obra, tivesse sido preconizada por Moholy-Nagy na década de 1930, difundiu-se apenas na década de 1960, cabendo a Palatnik destacado papel nesse quesito entre sua geração de artistas cinéticos.

Incentivado por Mavignier, o Cinecromático foi enviado pelo autor à I Bienal Internacional de São Paulo, mas por não se enquadrar em nenhuma das tradicionais categorias artísticas previstas no regulamento, o júri, impedido de premiá-lo, sugeriu sua aquisição para o acervo do Museu de Arte Moderna. [PEDROSA, 1975, p. 288-289].

Estranho à crítica, o que explica a escassez de textos referentes à proposta de Palatnik, a maioria ignorou a obra na abertura da Bienal, assunto que discutiremos adiante. Mas chamou atenção dos articulistas da imprensa, que, despreparados para refletir sobre algo inteiramente inusitado no mundo da arte, recorreram ao artista para conceder-Ihes entrevistas e responder às inquirições sobre o Cinecromático.

Em depoimento concedido ao jornal Tribuna da Imprensa [1951, p. 5], Palatnik esclarecia que iniciou a pesquisa almejando "fugir do determinismo 
que padroniza a atividade artística", sem ter ideia precisa de como atingir tal objetivo. Construiu, inicialmente, um caleidoscópio, que observou e manipulou exaustivamente, até se certificar das limitações do objeto para obter algum resultado satisfatório. Destacava, entretanto, que, por sua arbitrariedade, o caleidoscópio o colocou diante de vários problemas, como o jogo combinatório e a questão "estético-perceptiva" do objeto, pois independem do artista:

Cheguei à conclusão de que nem sempre os fatores pessoais vão decidir a estética visual - há outros elementos que participam, por exemplo: certa organização do espaço, as possibilidades da forma e da cor, as proporções em geral etc. Sabemos que é uma esfera ou um quadrado, mas o que necessitamos compreender é a proporção e o significado de tais formas em certa periferia, em certo espaço [PALATNIK, 1951, p. 5]

Afirmava, ainda, que ao pôr o caleidoscópio no espaço: "me deparei com problemas reais: o do movimento, o da ordem e o da cromática luminosa, que consegui [solucionar], depois, através da refração da luz pelo prisma" [PALATNIK, 1951, p. 5].

O objeto cinético dotado de luz/cor em movimento, graças à expertise do artista no emprego de recursos eletromecânicos, demoveu as formas e as cores de sua característica imobilidade e confinamento, para mostrá-las em permanente dissolução, expansão, explosão e transmutação, gerando matizes voláteis de cor-luz se propagando no espaço.

Nos inúmeros Cinecromáticos que o artista elaborou nos anos subsequentes, passou a construir os próprios motores elétricos com dimensões cada vez menores, para obter diferentes efeitos cambiantes e luminosos e uma gama mais variada de cores e formas, que promovem verdadeira dança no écran. Se o resultado final não deixa de remeter, de alguma maneira, à pintura abstrata, por ser gerada com pinceladas de luz e por "outorgar predominância à construção de estruturas em que o exercício da razão se impõe sobre a subjetividade" [BÉRTOLA, 1973, p. 122], se distanciava do processo pictórico convencional. E para além da geração de estímulos visuais e luminocromáticos misteriosos e fascinantes [formas instáveis e jogos cambiantes de cores], a arte cinética propõe "uma relação complexa entre mensagem visual e informação estética" [PIERRE, 2005, p. 27]. 


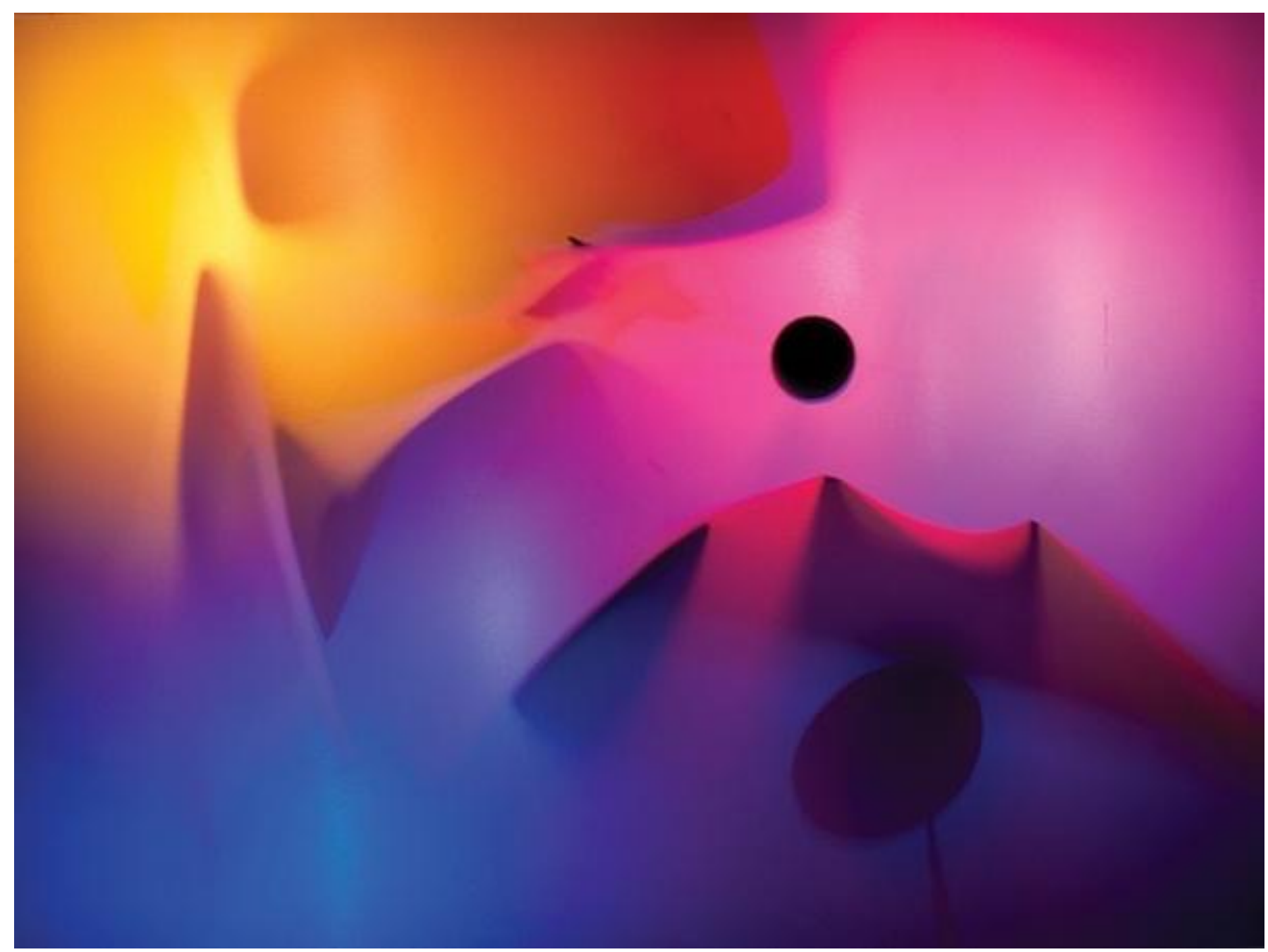

Fig. 1: - Abraham Palatnik. Aparelho Cinecromático, 1955.

[Fonte: Galeria Nara Rosler [SP]] 


\section{DO ESTRANHAMENTO INICIAL À RECEPÇÃO TARDIA DA CRÍTICA}

Se a obra de Palatnik despertou interesse e curiosidade do público visitante da I Bienal, a reação da crítica brasileira seria de perplexidade, não revelando grande entusiasmo ou empatia pelo Cinecromático. Isso explica por que apenas dois críticos mais familiarizados com as novas experimentações se incumbiram de esclarecer sobre as premissas estéticas e o funcionamento do aparelho luminocromático.

Em Introito à Bienal, publicado no jornal Tribuna da Imprensa[1951], Mário Pedrosa referia-se à recusa inicial da obra de Palatnik pelo júri da Bienal e fazia uma série de considerações sobre as experiências pioneiras dos artistas internacionais com a tecnologia e a luz, destacando Moholy-Nagy, cujas experimentações e os estudos da física moderna abriram novos caminhos para a arte. Discorria também sobre a especificidade funcional e estética do Cinecromático, projetando numa tela semitransparente um universo de formas abstratas e cores em movimento aparentemente arbitrário, que remetiam ao caleidoscópio e aos "afrescos de luz" de Moholy-Nagy.

Embora reconhecesse a ousadia e a originalidade do objeto cinético palatnikiano, Pedrosa referia-se à herança do artista húngaro, artista referência tanto para os pioneiros da arte cinética, como para os críticos que dialogaram com ela, o que leva a crer que Palatnik tivesse sido apresentado por Pedrosa à referida obra do artista húngaro:

Abandonando o pincel e o figurativo, decidiu-se [Palatnik], após um estágio abstracionista, a pintar com luz numa audaciosa tentativa de realizar uma das mais velhas "utopias artísticas", na expressão de Moholy-Nagy. [...].

O artista não se pode contentar com o velho métier pictórico, o pincel e as cores químicas pigmentárias. Para controlar, dirigir, plasmar a luz são necessários novos instrumentos e a familiaridade com as conquistas da ótica moderna, desde os problemas de colorometria até as virtualidades da luz artificial.

Palatnik está na linha dos pesquisadores de plástica de luz, isto é, dos efeitos de espaço-tempo sobre nossa sensibilidade. [PEDROSA, 1951, p. 7].

O crítico relacionava as cores da luz que emana do objeto cinético com certos matizes da pintura convencional, mesmo reconhecendo nelas qualidades próprias, o que as diferenciava da gama variada de tons obtidos com pigmentos minerais. Concluía a reflexão observando que, se Moholy-Nagy profetizou que o dinamismo plástico de seus "afrescos de luz iria animar edifícios inteiros ou as paredes das casas do futuro", esse prognóstico se tornou realidade com o advento dos aparelhos domésticos de televisão [PEDROSA, 1951]. 
No artigo A máquina de Abrahão Palatnik, publicado no Diário Carioca, também na inauguração da Bienal [20 de outubro de 1951], Antonio Bento se mostrou bem mais modesto em sua abordagem. Repetindo palavras do próprio artista, o crítico referia-se ao Aparelho Cinecromático "como uma máquina de projeção do tipo suigeneris, o que permitia associá-lo ao cinema, à lanterna mágica e ao caleidoscópio”. E justificava a recusa da obra pelo júri da Bienal, do qual ele foi um dos integrantes, afirmando que a comissão, em mensagem escrita, referia-se ao objeto como "importante manifestação da arte moderna" e considerava-a "digna de figurar no Museu de Arte Moderna de São Paulo", deferência que, segundo o crítico, equiparava-se ao prêmio, pois o objeto acabou adquirido pelo Museu patrocinador do evento.

No texto publicado alguns meses após o encerramento da I Bienal, Uma nova técnica na pintura moderna [1952], Walter Zanini refletia sobre o que chamou de "sentido estético-perceptivo" do objeto palatnikiano, afirmando que ele solucionou o problema da "cromática luminosa", por meio de "um sistema mecânico que transmite a luz movimentando-a na direção desejada". Estabelecia, ainda, analogia entre a pesquisa do artista brasileiro e as proposições dos futuristas italianos, e refletia sobre a contribuição de teóricos como Wertheimer à teoria da Gestalt e à percepção, base da pesquisa desenvolvida por Palatnik, enredamento teórico que atestava a sólida formação intelectual do historiador. Zanini concluía ressaltando o esforço do jovem artista brasileiro em diversificar a experiência estética, ironizando a oposição que Ihe faziam aqueles que, comodamente, não se propunham instaurar nenhum tipo de dúvida, preferindo repetir velhas e gastas formulações pictóricas:

Dá gosto ver um moço como Palatnik buscando, aflito, caminhos novos de expressão nos espaços sidéreos, enquanto os limitados acadêmicos ficam repintando pela multimilionésima vez os seus cachinhos de uva, bem bonitinhos, bem arranjadinhos, bem capazes de dar bom aspecto à casa onde o espírito é eterno ausente. [ZANINI, 1952, p. 6].

Os discursos dos citados críticos não encontraram grande interlocução, nem conseguiram dirimir a aversão ou a dificuldade de compreensão da arte cinética pela crítica conservadora, o que explica a lacuna e a quase completa ausência de reflexões sobre essa vertente artística no período que vai do término da I Bienal até quase o final da década de 1970. Basta citar que a primeira individual de Palatnik, realizada no Museu de Arte Moderna do Rio de Janeiro [1960], angariou a publicação do Jornal do Brasil de uma sequência de notas institucionais não assinadas, cuja função era divulgar a mostra, mas que pouco contribuiriam para alargar a visada cognitiva sobre as obras e a relação entre arte e tecnologia. 
A reflexão mais elucidativa sobre as obras de Palatnik apresentadas nessa exposição viria novamente de artigo de autoria de Mário Pedrosa, Arte e invenção[1960]. Chamava-as de "pintura de luz", geradoras de relações cromáticas que se diferenciavam dos preceitos teóricos e dos resultados pictóricos obtidos com pigmentos. Ressaltava o avanço das pesquisas do artista, por conseguir aperfeiçoar "o mecanismo das projeções", o que permitia iluminar, agora, mais homogeneamente todo o écran. O crítico concluía a reflexão desafiando o artista a diversificar seus inventos, recorrendo a novos dispositivos tecnológicos, embora isso já ocorresse desde o ano anterior:

Quando será que Palatnik, com o gênio inventivo que Deus lhe deu nos trará nova revolução técnica e estética, assenhoreando-se da eletrônica para ganhar melhor liberdade e variação nas suas experiências cinecromáticas? Se já se faz música eletrônica, porque esse talentoso não se decide a palmilhar o terreno inexplorado daquela ciência para criar também a pintura ou o cinecromatismo eletrônico? Já está na hora. [PEDROSA, 1960, p. 6].

O convite para a individual no MAM carioca coincidia com o aumento da circulação internacional da obra de Palatnik por instituições culturais estrangeiras, angariando também notória receptividade e interlocução da crítica. Claramente influenciado pelos escritos de Pedrosa, Jayme Maurício publicava, poucos dias depois da inauguração dessa mostra, na coluna que assinava no Correio da Manhã, denominada Itinerário das Artes Plásticas, uma sequência de tímidas notas sobre as obras expostas, não restritas às propostas cinéticas. Em matéria mais extensa, publicada pouco depois, Palatnik e a Antiteoria do Cinecromatismo [1960], o crítico não parecia devidamente preparado para aprofundar a reflexão sobre as obras. Limitou-se a fornecer informações sobre a formação do expositor e a transcrever trechos de depoimentos do próprio Palatnik a respeito de suas investigações estéticas, com destaque para o conceito de antiteoria. Embora afirmasse concordar apenas parcialmente com a visão do artista, transcreveu no texto o pensamento de Palatnik sobre a questão, sem pontuar em que consistia sua divergência desse conceito:

Antiteoria é a concretização da expressão na obra de arte. É aquilo que realmente se realiza no quadro, na escultura [...]. É aquilo que para ser percebido não precisa ser lembrado, indicado, sugerido, explicado ou teorizado pelo artista ou o crítico. O homem tem que ser estimulado a perceber por conta própria o que existe. O hábito de teorização é negativo, pois o ser inteligente tem habilidade intelectual suficiente para compreender qualquer teoria. Esta compreensão the dá uma segurança e tranquilidade mental tamanha que aceita mesmo as coisas que instintivamente não percebeu por si mesmo [PALATNIK apud MAURÍClO, 1960, p. 2]. 
O crítico francês Michel Ragon, depois de ver as obras cinéticas do brasileiro na VI Bienal de São Paulo [1961], publicou em Paris o texto Le mouvement dans I' art actuel[1962]. Começava por traçar um panorama da evolução e significado da Arte Cinética em todo o mundo, para depois referir-se aos Cinecromáticos de Palatnik como obras que nasceram da mesma vontade que alimentou os quadros luminosos movidos por mecanismos eletrônicos, de autoria de dois reconhecidos expoentes do gênero em todo o mundo: o franco-húngaro Nicolas Schöffer [1912-1992] e o engenheiro americano Frank Malina [1912-1981]. O crítico reconhecia, ainda, que os Aparelhos Cinecromáticos anteciparam em sete anos as experiências luminodinâmicas, apresentadas por Schöffer em Nova York [1957].

Entretanto, nem o aval do teórico francês à ousadia criativa do brasileiro ampliou o interesse da crítica local por suas obras cinéticas que, além de cinecromáticos, exibia na Bienal um naipe mais diversificado de objetos dotados de movimento.

Na França, a Arte Cinética foi exibida e incorporada definitivamente ao vocabulário artístico somente após a exposição Le Mouvement [1955] na Galeria Denise René, em Paris, com curadoria do sueco Pontus Hultén, denominação que rapidamente se universalizou. Nessa mostra, lançou-se um folder, cujos textos se tornaram conhecidos como Mani- festo Jaune. Mas ao apresentar a arte cinética à capital francesa, exibiu-se na mostra tanto obras dotadas de movimento real quanto pinturas óticas de artistas como Victor Vasarely, que apenas sugeriam efeitos dinâmicos.

\section{Como na época os Aparelhos Cinecromáticos de} Abraham Palatnik ainda não haviam circulado no exterior, o artista não integrou a mostra internacional. Apenas em 1966, quando da participação do brasileiro da mostra Kunst-Licht-Kunst, no Museu de Arte de Eindhoven, Holanda, é que, no texto introdutório do catálogo, o conhecido crítico e historiador da arte cinética, o franco-britânico Frank Popper, confirmava o pioneirismo de Palatnik na produção de "móbiles luminosos", posição que reafirmaria no livro Naissance de l'Art Cinetique [1967], incluindo nosso artista no rol dos pesquisadores de "obras luminocinéticas". A deferência ocorreu por o brasileiro participar da 32a Bienal de Veneza [1964] e de outras mostras internacionais, entre elas Le Mouvement II, na citada Galeria Denise René [1964], que teria formulado o convite ao artista depois que a própria galerista viu as obras do brasileiro naquela Bienal.

Repercussão não menos significativa foi o ensaio, de autoria também de Frank Popper, denominado Arte cinética [1968], publicado na revista paulista Artes [n. 15], em que relacionava os estudos da física e da ótica moderna com as novas pesquisas com a 
luz e o movimento. Os textos de autoria dos críticos europeus, decorrentes da ampla circulação da obra de Palatnik por vários países, começariam a romper lentamente a barreira da rejeição aos objetos cinéticos, sendo que o reduto da crítica brasileira ainda não havia se posicionado favorável a esse gênero de trabalhos artísticos. Confirmava, assim, a dificuldade de compreender e dialogar com objetos construídos com materiais industriais e sofisticada tecnologia, que subvertiam o conceito tradicional de escultura e até de obra de arte.

Na década de 1970, quando a Arte Cinética dava sinais de ter cumprido seu ciclo no mundo e a obra de Palatnik já havia transitado por importantes instituições culturais de todos os continentes, continuava despertando pouco interesse no Brasil, posição que se manteve praticamente inalterada até a década seguinte. Curiosamente, apenas em 1977 é que o artista realiza, na Galeria Bonino do Rio de Janeiro, talvez sua mais significativa exposição comercial, sendo que a crítica praticamente a ignorou. Coube a Roberto Pontual publicar no Jornal do Brasil[1977] o texto mais elucidativo sobre a exposição, embora a reflexão se respaldasse em falas do artista. $\bigcirc$ crítico iniciava o discurso destacando a importância da mostra, cujo artista não lhe era inteiramente desconhecido:

Se me perguntasse que retrospectiva de artistas brasileiros julgo de realização mais urgente e oportuna, neste momento, eu não relutaria em colocar entre elas a de Abraham Palatnik. [...]. A certeza da necessidade de abordar e compreender panoramicamente a obra de Palatnik não é, para mim, coisa de hoje; veio-me desde que o visitei pela primeira vez no seu apartamento de Botafogo, em 1972 [PONTUAL, 1977].

Entretanto, logo em seguida fazia uma espécie de mea culpa, ao afirmar que a atenção sobre a exposição foi despertada por carta que Ihe enviou de Hamburgo Almir Mavignier, ressaltando o significado da obra e da trajetória de Palatnik, entre outros aspectos, como o de ser ele

[...] um dos primeiros brasileiros dispostos a absorver a rigorosa disciplina da linguagem construtivista entre nós, ao fim da década de 40. Esta menção e a presença da individual de Palatnik, atualmente na Galeria Bonino, do Rio, indicam os marcos extremos, até aqui, de uma carreira e de uma obra que o público precisa ver e conhecer meIhor [PONTUAL, 1977].

Apenas da década de 1980 até o início deste século é que a produção de Palatnik - em seus diferentes suportes e modalidades - passou a angariar maior espaço na mídia e nas instituições culturais brasileiras. Entretanto, sua obra ainda é pouco conhecida e estudada, sem contar que não se publicou, até então, um estudo acadêmico refletindo exclusivamente sobre sua produção cinética. Assim, este texto presta tributo ao artista, falecido em 2020, vítima de Covid-19. Revista Poiésis, Niterói, v. 23, n. 39, p. 170-186, jan./jun. 2022. [DOl: https://doi.org/10.22409/poiesis.v23i39.50822] 
BARRET, Cyril. A Arte Cinética. In STANGOS, Nikos. Conceitos de Arte Moderna. Tradução de Álvaro Cabral. Rio de Janeiro: Jorge Zahar, 1991, p. 150-159.

BENTO, Antonio. A Máquina de Abrahão Palatnik. Diário Carioca, Rio de Janeiro, 20 de outubro de 1951, p. 6.

BÉRTOLA, Elena de. Arte Cinético. Em movimento y la transformatión: análisis perceptivo y funcional. Buenos Aires: Nueva Visión, 1973.

BIHALI-MERIN, Oto. La fin de l'Art à l'ère de la Science? Bruxelas: La Conaissance, 1970.

MAURíCIO, Jayme. Palatnik e a "Antiteoria" do Cinecromatismo. Correio da Manhã, Rio de Janeiro, 11 de abril de 1960 , p. 2 (2․ Caderno).

PALATNIK, Abraham. Na I Bienal: a magia de Palatnik. Luz no lugar da tinta (depoimento). Tribuna da Imprensa, Rio de Janeiro, 5 de novembro de 1951, p. 5.

PARENTE, André (org). Imagem Máquina. Rio de Janeiro: Edições 34, 1993.

PEDROSA, Mário. Arte e Invenção. Jornal do Brasil, Rio de Janeiro, 23 de março de 1960, p. 6 (1 o Caderno). 
PEDROSA, Mário. Introito à Bienal. Tribuna da Imprensa, Rio de Janeiro, 20 de outubro de 1951, p. 7.

PedrosA, Mário; AMARAL, Aracy, (org.). Mundo, Homem, Arte em crise. São Paulo: Perspectiva, 1975.

PIERRE, Arnauld. L'Oeil Multiplié. In L'Oeil Moteur: art optique et cinétique, 1950-1975. Estrasburgo: Les Musées de Strasbourg, 2005, p. 20-29.

PONTUAL, Roberto. Movimento: do motor, do olho, da gente. Jornal do Brasil, Rio de Janeiro, 14 de maio de 1977, p. 4 (Caderno B).

POPPER, Frank. Naissance de I’Art Cinetique. Paris: Gauthier-Villards, 1967.

RAGON, Michel. Le mouvement dans I' art actuel, Jardin des Arts, Paris, n. 95, outubro de 1962. p. 54-61.

TOMKINS, Calvin. Duchamp. Tradução de Maria Thereza R. Costa. São Paulo: Cosac Naify, 2004.

ZANINI, Walter. Uma nova técnica na pintura moderna. O Tempo, São Paulo, 1 de junho de 1952. 